\title{
Anaesthetic Management of Liver Resection Surgery in Birendra Army Hospital
}

\author{
KC NB ${ }^{1}$, Rai $\mathbf{S}^{1}$, Panta $\mathbf{S}^{1}$ \\ ${ }^{1}$ Nagendra Bahadur KC, ${ }^{1}$ Sashi Rai, ${ }^{1}$ Sunita Panta, Department of Anaesthesiology, Shree Birendra \\ Hospital
}

\begin{abstract}
This is a case report of a $65 \mathrm{yrs}$ old male patient who underwent resection of left lateral segment (segment23) of Liver for advanced Hepatocellular carcinoma. The case was performed under general anesthesia combined with epidural analgesia for post op pain management. During resection, Hypotension is maintained to reduce bleeding.
\end{abstract}

Key words: Blood and CVP pressure, Epidural analgesia, General Anesthesia, Hepatocellular carcinoma (HCC), left lateral segmentectomy

\section{Introduction}

Hepatocellular carcinoma (HCC) is frequently diagnosed at advanced stages and has a high mortality rate. Surgical resection is an important potentially curative therapy for liver tumors ${ }^{1}$. Though Birendra Army hospital is a referral centre, it has its own limitation as far as advanced technology and equipment is concerned. Liver resection is considered a demanding surgery even in high volume hepatobiliary centres, This kind of surgery was performed for the first time in this hospital with positive outcome.

\section{Case Report}

65 years old male patient, diagnosed case of Hepatocellular carcinoma, planned for left lateral segmentectomy (segment 2-3) of Liver. He was admitted with history of decreased appetite, nausea and rapid weight loss since 3 months. In Pre anesthetic checkup, patient is malnourished, thinly built, with weight $46 \mathrm{Kg}$. He has no history of past operation and medical illness.

In personal history, he is smoker and occasional alcohol ingestion. On examination, his vitals are normal and chest is clear, Abdomen is soft with mildly tender in Address for correspondence: drnkcbinita@gmail.com right hypochondriac region. In investigation reports, his Hemoglobin is $11.7 \mathrm{Gm} \%$, INR 1.16, platelet 1,98,000/ $\mathrm{mm} 3$, Renal function test is within normal limit, Chest $X$ ray and ECG is normal. Liver function test is deranged with serum bilirubin 10.2(T) and 5.2(C); Alkaline Phosphatase 3524 U/L; SGPT 190 IU/L. In CT report, there is a mass in Liver segment 2-3 and gall bladder is not visualized.

One night before of operation, Patient is again re-evaluated and given tab. Diazepam $5 \mathrm{mg}$ HS stat. Patient is categorized as ASA class III. Patient Party is explained about the operation and its consequences and advised to arrange 4 units of whole cross matched Blood and 4 unit of Fresh Frozen Plasma.

In operation theatre, Twol/ $/ \mathrm{line}$, one $16 \mathrm{~g}$ and one $18 \mathrm{~g}$ is opened and routine monitors are put on. First of all Epidural catheter is placed in T10 level and after confirmation with Injection Lignocaine $2 \%$ with Adrenaline $3 \mathrm{ml}$, Morphine $3 \mathrm{mg}$ is given for intra op and post op pain management. Then patient is anesthetized after giving $\mathrm{I} / \mathrm{V}$ injection midazolam $2 \mathrm{mg}$, morphine $3 \mathrm{mg}$, Sodium 
Thiopental $225 \mathrm{mg}$ and intubated with ETCT $8 \mathrm{~mm}$ size after giving Suxamethonium $100 \mathrm{mg}$. Then Anesthesia is maintained with Halothane and Vecuronium. Then CVP line is kept in Right internal jugular vein and continuous CVP pressure is monitored. Initial CVP pressure is 11 $\mathrm{cm}$ of water, and it is maintained at $10-12 \mathrm{~cm}$ of water through out operation. Then Urinary catheter is kept and urine output is monitored hourly. Then surgery is started and total time of surgery is three hours. During intra operative period, initially blood pressure is maintained $90-120 / 60-90 \mathrm{~mm}$ of $\mathrm{Hg}$ and pulse is ranging $90-120 /$ mint.When resection of left lateral segment (segment23 ) is started Surgeon ask to decrease Blood pressure and CVP pressure to reduce bleeding. To reduce Blood pressure and CVP pressure, we gave epidural injection of Bupivacaine $0.125 \% 12 \mathrm{ml}$, and Halothane inhalation increased up to $2 \%$, then we gave I/V injection Lasix 40 $\mathrm{mg}$, injection Nitroglycerine 50 micro Gm. Blood Pressure dropped up to $60-70 / 40-50 \mathrm{~mm}$ of $\mathrm{Hg}$ and maintained in that level Heart rate is increased up to $140 /$ mint and to reduce it, Injection Esmolol $20 \mathrm{mg}$ is given and heart rate is maintained in 100-120/mint, but CVP pressure can't reduce below $10 \mathrm{~cm}$ of $\mathrm{H} 2 \mathrm{O}$. Parenchymal Resection of Liver is done with the help of Harmonic ultrasonic dissector and resection period is around 45 minutes and

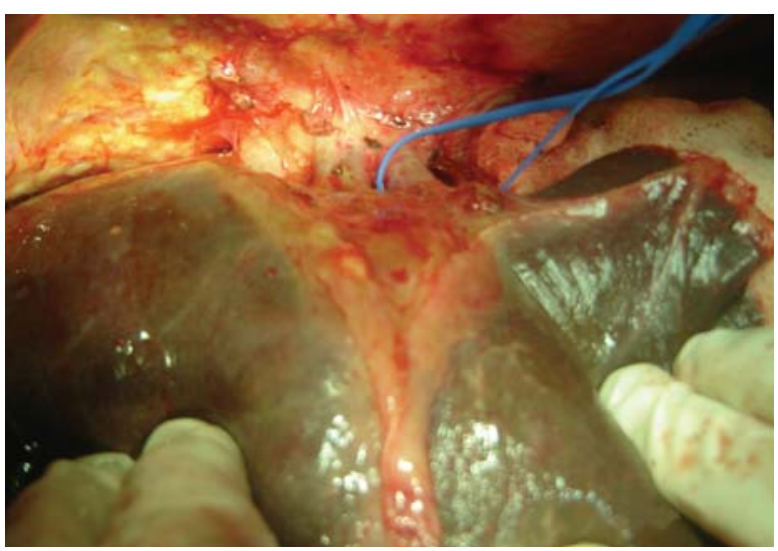

Fig. 1

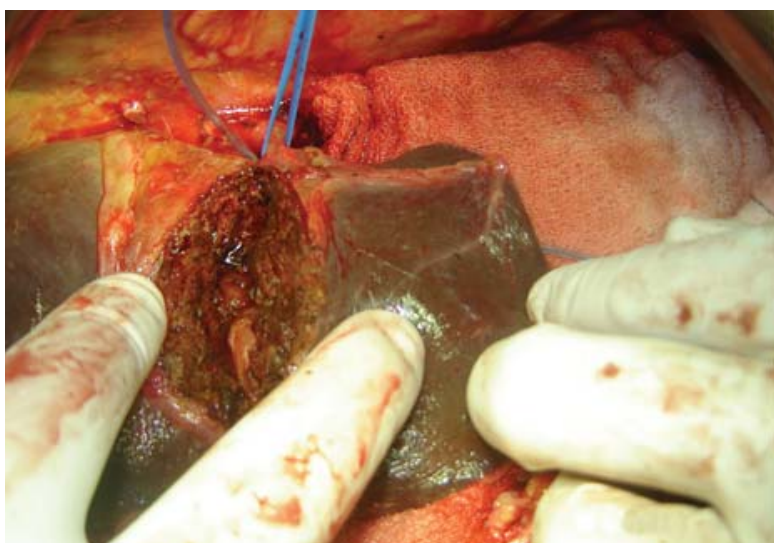

Fig. 3 there was very minimal bleeding (Fig 1,2,3,4). During this period Oxygen saturation is maintained $99-100 \%$. After resection of liver parenchyma, intra hepatic bile ducts and oozing vessels are ligated. Then surgeon ask to bring Blood Presser back to normal level to check whether there is any oozing or bleeding, so Halothane inhalation reduced to $0.5 \%$ and Injection Mephentermine is given in increments' of $6 \mathrm{mg}$ in each time and given total $24 \mathrm{mg}$ and Blood pressure increased up to 110/70 $\mathrm{mm}$ of $\mathrm{Hg}$. There was no bleeding at resected site. Abdomen is closed in layers after putting drain. Later on, Blood pressure maintained 100-130/60-90 mm of $\mathrm{Hg}$ and heart rate $90-120 /$ mint till patient is shifted to post op ward. Total intra operative blood loss is Approx $300 \mathrm{ml}$, urinary out put is $900 \mathrm{ml}$. Total fluid received is Gelofusine (colloid) $500 \mathrm{ml}$, Ringer lactate $1000 \mathrm{ml}$ and normal saline $1000 \mathrm{ml}$. Post operatively planned to put patient in elective mechanical ventilator support for over night and put in SIMV mode with I/V sedation and epidural analgesia (Injection Bupivacaine 0.125\% $10 \mathrm{ml}$ SOS). In $1^{\text {st }}$ post operative day, Vitals are within normal limit and patient is comfortable so extubated. Epidural Analgesia is maintained for $72 \mathrm{hrs}$ then removed. CVP line also removed on $3^{\text {rd }}$ Post op day and pt is transferred to ward.

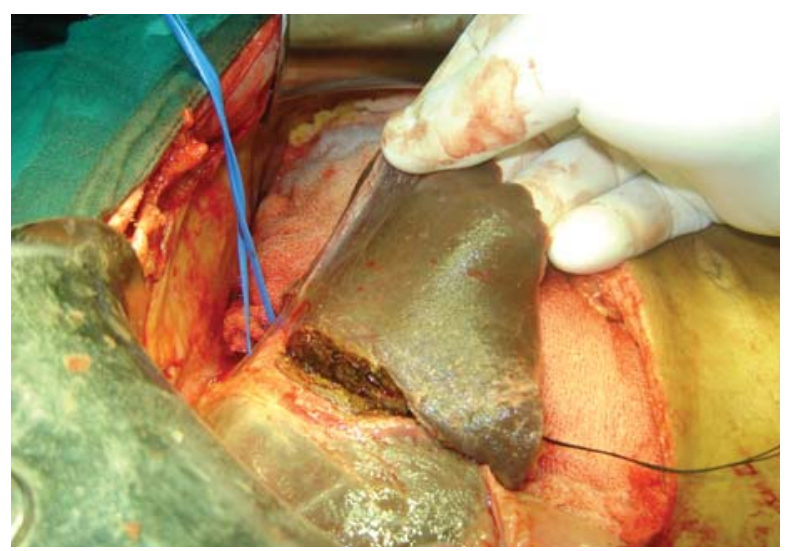

Fig. 2

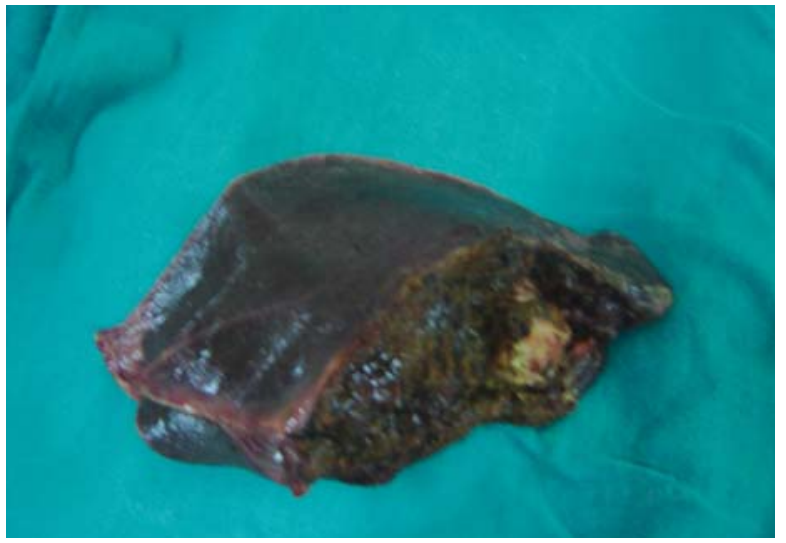

Fig. 4 


\section{Discussion}

Hepatocellular carcinoma ( $\mathrm{HCC}$ ) is one of the most common malignant tumors worldwide. In order to reduce morbidity and mortality from HCC, early diagnosis and the Development of novel systemic therapies for advanced disease; including drugs; gene and immune therapies as well as primary HCC prevention are of paramount importance ${ }^{2}$. Surgical resection is also an important potentially curative therapy for hepatocellular carcinoma. One of most important aspect of anesthetic management during resection of major part of diseased liver part is to decrease bleeding and to preserve the splanchnic perfusion. Poozar-Lukonorvvic, $\mathrm{N}$ et al, had published an article with conclusion that Epidural block, combined with general anesthesia improved splanchnic perfusion and Liver oxygen delivery. Thus routine use of this type of anesthesia is justified and could be recommended in liver surgery ${ }^{3}$. In our set up also, epidural anesthesia is always used combined with general anesthesia in major abdominal surgery and in this case also epidural catheter is placed at T10 level before induction and given morphine for intra and post op pain management. Local Anesthetic drug, Bupivacaine $0.125 \% 12 \mathrm{ml}$ is given through epidural at the time of resection to decrease blood pressure and CVP pressure with improving splanchnic perfusion. In different studies it is mentioned that reduce CVP pressure is one of the important strategy to reduce bleeding. In one study it is concluded that the volume of blood loss and blood transfusion during liver resection correlates with the CVP during parenchymal transection. Lowering the CVP to less than $5 \mathrm{mmHg}$ is a simple and effective technique to reduce blood loss during liver resection and delete the need for blood transfusion with its hazards ${ }^{4}$.Major resection with Low CVP allowed easy control of the hepatic veins before and during parenchymal transection. The anesthetic technique, designed to maintain Low CVP during the critical stages of hepatic resection, not only helped to minimize blood loss and mortality but also preserved renal function ${ }^{5}$. In one study, CVP during hepatic resection was not associated with intraoperative blood loss in living liver donors, suggesting that CVP may not be an important factor in predicting blood loss during hepatectomy in healthy subjects ${ }^{6}$. In this case, we could not reduce CVP pressure below $10 \mathrm{~cm}$ of water, but there was no significant bleeding during resection, it may be due to maintenance of low Blood pressure. In literature there are other methods too, to reduce bleeding during resection. In one study, it is suggested that the use of Aprotinine significantly reduces blood loss and transfusion requirements in patient undergoing elective liver resection through subcostal incision ${ }^{7}$. Vascular occlusion is used to reduce blood loss during liver resection surgery. There is considerable controversy regarding whether vascular occlusion should be used or not during elective liver resections but intermittent vascular occlusion seems safe in liver resection. However, it does not seem to decrease morbidity. Among the different methods of vascular occlusion, intermittent portal triad clamping has most evidence to support the clinical application. In our case we have done inflow control and out flow control of portal, hepatic artery and hepatic veins, this procedure also help to reduce bleeding ${ }^{8}$. Despite these improvements, partial liver resections remain a major surgical procedure and carry the risk for excessive blood loss and a subsequent need for blood transfusion. Blood transfusions have been associated with systemic side effects, such as depression of the immune system. Several studies have suggested that perioperative blood loss or transfusions have a negative impact on postoperative outcome in Liver resection. Blood transfusion may have an impact on tumor recurrence has been found for patients with early stages of HCC. However, overall, no such effect could be demonstrated for patients undergoing partial liver resection for late stages of $\mathrm{HCC}^{9}$. In our case, Blood loss was very minimal that is only $300 \mathrm{ml}$ and Blood transfusion was not required.

\section{Conclusion}

Anaesthetic management during liver resection is challenging as hypotension and low CVP should maintained to reduce bleeding with preserving circulation to vital organs. In this case, hypotensive surgery is obtained but definitive low CVP could not be attained. This case is done successfully for the first time in this hospital without any intra op and immediate post op complication.

\section{References}

1. Treatment options for hepatocellular carcinoma.: Sandhu DS, Tharavil VS, Lai JP, Roberts LR Expert Rev Gastroenterol Hepatol. 2008 Feb;2(1):81-92

2. Treatment of hepatocellular carcinoma.: Blum HE. Best Pract Res Clin Gastroenterol. 2005 Feb;19(1):129-45

3. Influence of epidural Block on splanchnic perfusion in large liver resection.: Pozar-Lukanorvik, N, Paver-Erzen V, Gadzijev, EM. British J. Anesthesia, 1999,82:43 
4. Low central venous pressure anesthesia in major hepatic resection.:EID EA, Sheta SA, Mansour E. Middle East J Anesthesiol. 2005 Jun;18(2):367-77.

5. Perioperative outcomes of major hepatic resections under low central venous pressure anesthesia: blood loss, blood transfusion, and the risk of postoperative renal dysfunction: Malendez LA, Arslan V, Fischer ME, Wuest D, Jarnagin WR, Fong Y, Blumgart LH. J Am Coll Surg. 1998 Dec;187(6):620-5.

6. Association between central venous pressure and blood loss during hepatic resection in 984 living donors: Kim YK, Chin JH, Kang SJ, Jun IJ, Song JG, Jeong SM, Park JY, Hwang GS. Acta Anaesthesiol Scand. 2009 May;53(5):601-6.
7. Aprotinine reduces blood loss in patients undergoing elective liver resection.: Lentschener, Claude, MD; Benhamom,Dan, MD; Mercier, Fredenic J, MD. Anesthesia and Analgesia ;April 1997, volume 84, no 4.

8. Withdrawn Methods of vascular occlusion for elective liver resections:: Gurusamy KS, Sheth h, Kumar Y, Sharma D, Davidson BR; Cochrane Database Syst Rev. 2009 Jan 21;(1):CD006409.

9. Impact of blood loss on outcome after liver resection: de Boer MT, Molenaar IQ, Porte RJ; Dig Surg. 2007;24(4):259-64. Epub 2007 Jul 27. 